\title{
Energy Dependence of Etch Pit Diameter in a CR-39 Detector for $a$-Particles with the Energy from 1.29 to $5.48 \mathrm{MeV}$
}

\author{
Nobuhito Ishigure and Osamu MatsuoKA \\ Division of Comparative Radiotoxicology, National Institute of Radiological Sciences \\ 4-9-1, Anagawa, Chiba-shi 260, Japan \\ Received April 26, 1982
}

\begin{abstract}
The characteristics for $\alpha$-particle recording of CR-39 plastics was studied for practical use. Sample detectors were irradiated with $\alpha$-particles at normal incident angle. The energy was varied from 1.29 to $5.48 \mathrm{MeV}$. Tracks of $\alpha$-particles could sufficiently be recognized through the etch pit observation with 1 hour etching in $30 \%$ solution of $\mathrm{NaOH}$ at a temperature of $70^{\circ} \mathrm{C}$. The etch pit diameter decreased almost linearly with the energy of $\alpha$-particles at the early stage of etching, which suggested the possibility of the estimation of $\alpha$-particle energy. The energy resolution was evaluated from the FWHM of the measured distribution of etch pit diameters and found to be about $1.8 \mathrm{MeV}$ for 1,2 and 3 hour etching.
\end{abstract}

Key Words: CR-39 plastic track detector, etch pit diameter, $\alpha$-energy dependence

\section{Introduction}

Solid state nuclear track detector (SSNTD) has found wide application to various fields such as health physics, radiation physics, nuclear physics and archeology because of its simplicity in handling and availability at a low price ${ }^{1,2)}$. It is of considerable current interest to make clear the recording characteristics for lightly charged ions in different SSNTD particularly for the application to the field of health physics. Cellulose nitrate $(\mathrm{CN})$ has hitherto been applied as the most sensitive material on $\alpha$-particles ${ }^{3}$. Allyl diglycol carbonate, called as CR-39, has recently been found to possess better characteristics in $\alpha$-particle recording than $\mathrm{CN}$ : for example, high sensitivity, uniformity of response and superb optical quality ${ }^{1), 4)}$.

SSNTD is of extensive use for the dosimetric purpose relating to a research project on biological effect of internal irradiation by $\alpha$-particles. The recording characteristics of CR-39 for $\alpha$ particles are then investigated for practical use; in the present paper is reported the study mainly on the energy dependence of etch pit diameter.

\section{Experimental}

CR-39 samples, cut from a $1.6 \mathrm{~mm}$ thickness plate (Solar Optical Japan, Osaka, Japan), were irradiated with normal incident $\alpha$-particles from an ${ }^{241} \mathrm{Am}$ electrodeposited source in a vacuum chamber ${ }^{5)}$. The energy of $\alpha$-particles was varied over the range from 1.29 to $5.48 \mathrm{MeV}$ by replacing the absorber of thin polymer films. The energy spectrum was measured with a solid state detector of Si surface barrier type mounted in the vacuum chamber. The examples of spectra are shown in Fig. 1. Since the FWHM

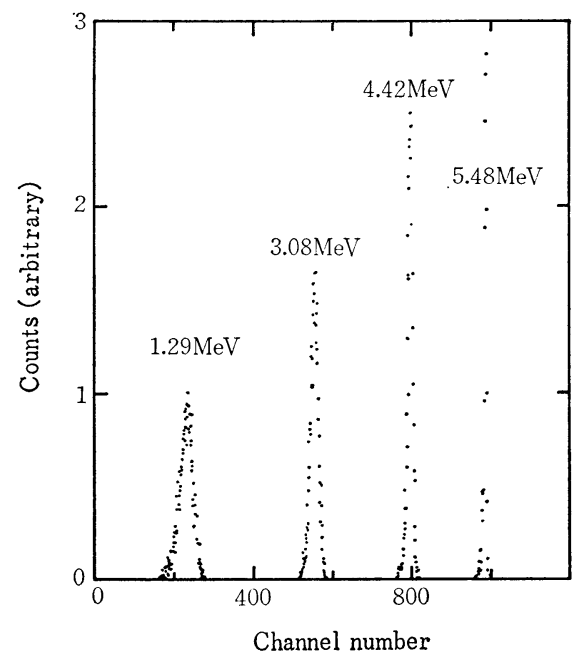

Fig. 1 Energy spectra of $\alpha$-particles used for irradiations. 
was small, ranging from $0.6 \%(5.48 \mathrm{MeV})$ to $15 \%(1.29 \mathrm{MeV})$, it was possible to study the energy dependence of etch pit diameter.

The irradiated samples were etched in $30 \%$ solution of $\mathrm{NaOH}$ in a bottle without stirring by ultrasonic at a temperature of $70^{\circ} \mathrm{C}$, using a water bath incubator (MODEL BT45, Yamato, Tokyo, Japan) at a constant temperature within $\pm 0.2^{\circ} \mathrm{C}$. To avoid the change of $\mathrm{NaOH}$ concentration caused by evaporation and moisture absorption during etching, the bottle mouth was sealed with a teflon sheet. The etching time was varied from 1 to 10 hours. After etching, the $\mathrm{NaOH}$ solution being on the surface of the samples was washed away by tap water and the samples were soaked in distilled water for scores of minutes.

Photographs of the etched samples were taken through an optical microscope ( $\times 100$ to $\times 400$ magnifications). The negatives were projected with a photographic enlarger or a slide projector. On the image thus enlarged the number and the diameters of etch pits were measured.

\section{Results and Discussions}

3.1 Photograph of etch pits in CR-39 induced by $\alpha$-particles

Figure 2 shows the etch pits observed in CR-39 which was irradiated with $5.48 \mathrm{MeV}$ $\alpha$-particles and etched for 4 hours. The etch pits could be recognized distinctly because of the striking contrast and the smoothness of

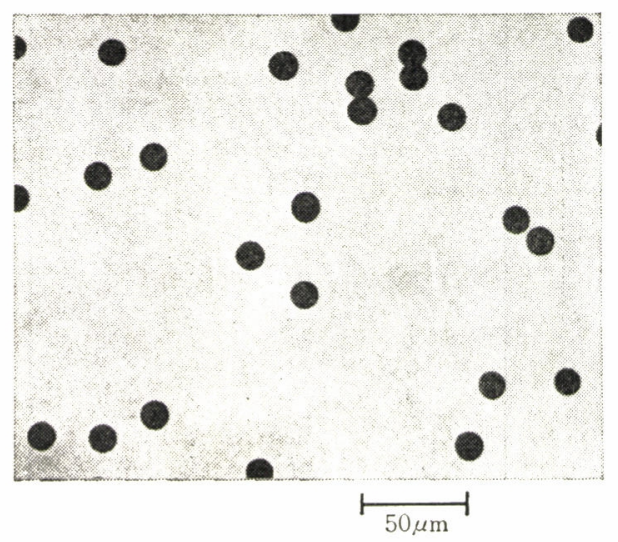

Fig. 2 Photograph of the etch pits observed in a CR-39 detector irradiated with $5.48 \mathrm{MeV}$ $\alpha$-particles and etched for 4 hours. the detector surface. While the distinctness depended on the etching time and $\alpha$-particle energy, the contrast was always strong enough for the measurement.

The etch pit diameters appeared to be all alike. This fact suggested the isotropy in construction of etch pits and the uniformity in constituent of the detector material and raised a hope for the possibility of the estimation of $\alpha$-particle energy through the etch pit diameter.

\subsection{Recording efficiency as a function of etching time}

The number of $\alpha$-particle tracks revealed by etching for different times was counted and compared with the number of incident $\alpha$-particles. The results for 1.29 and $5.48 \mathrm{MeV}$ are shown in Fig. 3. The error bar shows the

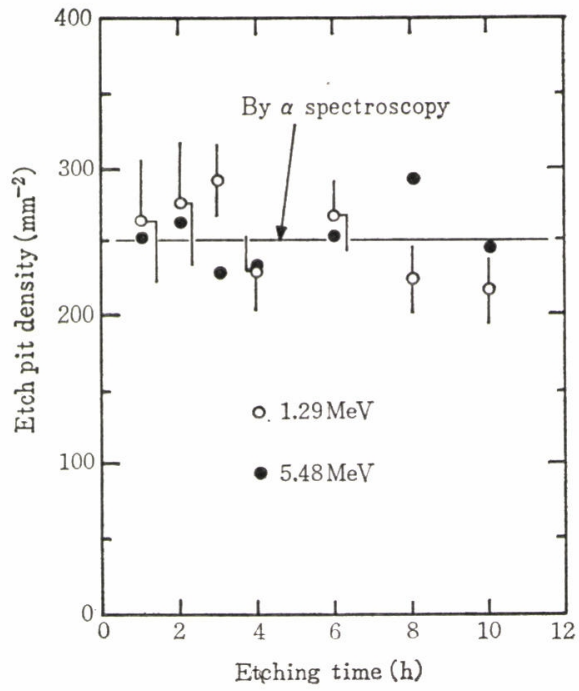

Fig. 3 Etch pit density against etching time.

square root of the number of etch pits on the assumption of Poisson distribution in the etch pit counting. The recording efficiency for normal incident $\alpha$-particles was $100 \%$ independent of the etching time between 1 and 10 hours and also of the $\alpha$-particle energy between 1.29 and $5.48 \mathrm{MeV}$. This fact suggested that the etching time does not have to be controlled so severely for the recording efficiency. In the case of very low density, longer period of etching was preferable to lower the magnification and to broaden the field of the view through a microscope. 
3.3 Distribution of etch pit diameters

The distribution of etch pit diameters was obtained as shown in Fig. 4: the results for the irradiation with $1.29 \mathrm{MeV} \alpha$-particles and for the etching time of $1,3,6$ and 10 hours. The numbers counted were 40 pits for 1 hour etching and about 80 pits for the others. The mean diameter and the absolute standard deviation increased with the etching time.

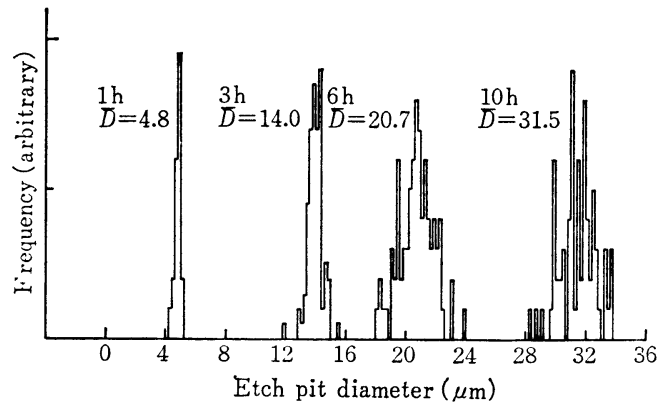

Fig. 4 Diameter distributions of etch pits induced by the irradiation with $1.29 \mathrm{MeV} \alpha$-particles and etched for $1,3,6$ and 10 hours.

The conformity to Gaussian distribution was certified by plotting the diameter distribution data on a sheet of normal probability paper. The relative standard deviation was small as expected from the observation through a microscope.

3.4 Energy dependence of etch pit diameter

The results for the mean diameter of etch pits as a function of etching time are

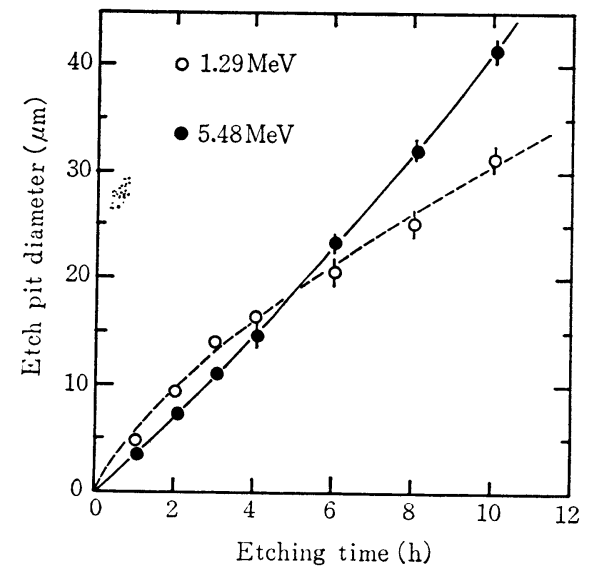

Fig. 5 Etch pit diameter as a function of etching time for the irradiation with 1.29 and 5.48 $\mathrm{MeV} \alpha$-particles. shown in Fig. 5 for, as examples, 1.29 and 5.48 MeV $\alpha$-particles. The error bar shows the standard deviation of the measured diameter distribution. The etch pit grew in size approximately at a constant rate for $5.48 \mathrm{MeV}$. In the case of the lower energy, as observed for 1.29 MeV, the slope of the curve decreased gradually with the etching time except for the first stage of etching. The diameter was larger for $1.29 \mathrm{MeV}$ than for $5.48 \mathrm{MeV}$ early in etching, but the difference was reduced gradually and at 5 hours of the etching time a reversion in the diameters between 1.29 and $5.48 \mathrm{MeV}$ occurred.

The energy dependence of etch pit diameter is shown in Fig. 6 for the etching time of, as

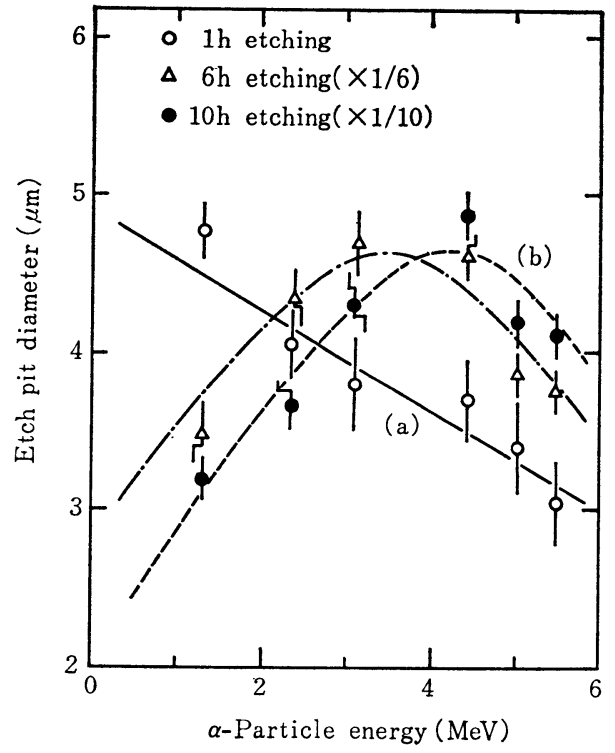

Fig. 6 Dependence of etch pit diameter on the energy of $\alpha$-particles for the etching time of 1,6 and 10 hours.

examples, 1, 6 and 10 hours. The etch pit diameter decreased approximately at a constant rate with the energy of $\alpha$-particles for 1 hour etching. Such a linearity was found up to 3 hour etching. With proceeding etching more than 3 hours, the discrepancy from a straight line was increasingly noticiable at low energy and finally the curve showed a distinct peak as observed for 10 hour etching, where unique relation between the $\alpha$-particle energy and the diameter was already lost.

According to a simple chemical kinetics con- 
sideration $^{6)}$, the track etching velocity $V_{\iota}$ can be expressed as a function of primary specific ionization rate $I$ :

$$
V_{t}=V_{o} \exp \left[\alpha\left(I-I_{l}\right) / k T\right]
$$

where $V_{o}$ is bulk etching velocity, $I_{t}$ threshold of $I$ for etchable damage, $T$ temperature of etching solution, $k$ Boltzmann's constant and $\alpha$ a constant. $V_{l} / V_{g}$ can be written as

$$
V_{t} / V_{o}=\exp \left[\alpha\left(\frac{\beta}{E}-I_{t}\right) / k T\right]
$$

considering that $I$ is approximately in inverse proportion to the energy of $\alpha$-particles $E$ within a given energy range, $I=\beta / E$. This indicates that $V_{t} / V_{g}$ decreases with increasing energy. As etch pit diameter $D$ can be expressed using such a ratio of $V_{t} / V_{o}$ and etching time $t$ as

$$
D=2 V_{0} t\left[\frac{V_{t} / V_{0}-1}{V_{t} / V_{0}+1}\right]^{1 / 2}
$$

the diameter increases monotonously with $V_{t} / V_{g}$. Therefore the diameter decreases with increasing $\alpha$-energy as curve (a) in Fig. 6.

The cause of the appearance of the curve (b) in Fig. 6 may be attributed to the fact that the shape of etching time vs. diameter curve depends on the variation of ionization density along the $\alpha$-particle track and the depth of track end point in a CR-39 detector ${ }^{7)}$. As the ionization density follows the well-known Bragg curve, the track etching velocity increases along the $\alpha$-track up to the vicinity of its end point. Therefore the curve of the diameter vs. etching time would be essentially a sinusoidal type having an inflection point where the etching proceeds further up to the vicinity of the track end point. As the length of the $\alpha$-track increases with $E^{3 / 2}$ within a given energy range, the inflection point will appear at the earlier stage of the etching for the lower energy of $\alpha$-particles. A reversion in diameter between the lower and the higher energy would thus occur at a longer etching time.

3.5 Energy estimation through etch pit diameter

The fact that etch pit diameter decreased linearly with the energy of $\alpha$-particles at the short etching time suggested the possibility in energy estimation through the measurement of etch pit diameter within a limitted etching con- dition. The energy resolution $\varepsilon$ was estimated by the following calculation for etching time from 1 to 3 hours.

$$
\begin{aligned}
\varepsilon= & \Gamma_{1 / 2} \times|\Delta E / \Delta D|=2.35 \times(\text { S. D. }) \\
& \times|\Delta E / \Delta D|
\end{aligned}
$$

where $\Gamma_{1 / 2}$ is FWHM in the distribution of etch pit diameters, S.D. standard deviation on the assumption of Gaussian distribution and $|\triangle E / \Delta D|$ absolute slope of the diameter vs. $\alpha$-particle energy curve such as curve (a) in Fig. 6. As significant dependence of $\varepsilon$ on the energy of $\alpha$-particles was not found, the $\varepsilon$ for each energy was averaged to obtain the energy resolution for each etching time. The results were $(1.70 \pm 0.33) \mathrm{MeV}$ for 1 hour, $(1.76 \pm 0.49)$ $\mathrm{MeV}$ for 2 hour and $(1.82 \pm 0.23) \mathrm{MeV}$ for 3 hour etching.

A detector was irradiated with 2 different $\alpha$-beams, 5.48 and $1.29 \mathrm{MeV}$. The fluence ratio was $2(5.48 \mathrm{MeV}): 1(1.29 \mathrm{MeV})$. A photograph of the detector etched for 2 hours is shown in Fig. 7. Two larger pits would be due to 1.29 MeV $\alpha$-particles and 4 smaller and darker ones to $5.48 \mathrm{MeV}$, taking into account the fluence ratio.

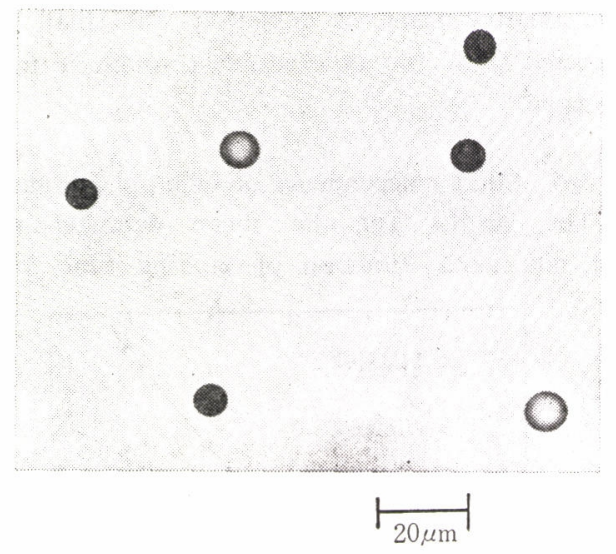

Fig. 7 Photograph of the etch pits induced by the irradiation with 2 different $\alpha$-beams, 1.29 and $5.48 \mathrm{MeV}$, and by the etching for 2 hours.

The diameter distributions for 2 and 8 hour etching are shown in Fig. 8. Two different groups could be recognized. The number of pits in the group with the larger diameter in 2 hour etching was $1 / 3$ of the total number, which just agreed with the fraction of the fluence 

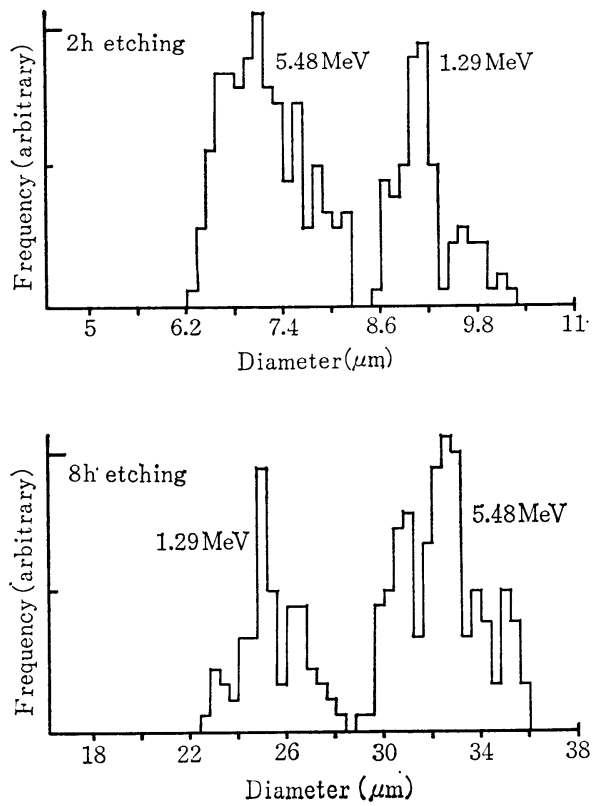

Fig. 8 Diameter distributions of etch pits induced by irradiation with 2 different $\alpha$-beams, 1.29 and $5.48 \mathrm{MeV}$, and by the etching for 2 and 8 hours.

for $1.29 \mathrm{MeV}$ in the total fluence of $\alpha^{-}$ particles. This relation also could be seen for the number of the pits in the group with the smaller diameter in 8 hour etching. It was clear for this reason that the etch pits in the group with the smaller number of pits were due to $1.29 \mathrm{MeV} \alpha$-particles and those with the larger number to $5.48 \mathrm{MeV} \alpha$-particles. The cause of the reversion in the diameter of the 2 different groups between 2 and 8 hour etching was as discussed in 3.4. When the difference of energy between 2 groups of $\alpha$-particles is large as tested here, the distinction between them through the measurement of etch pit diameter was possible with the energy resolution of 1.8 MeV.

\section{Conclusion}

The recording characteristics of CR-39 for $\alpha$-particles was studied through the irradiation with comparatively well defined $\alpha$-particles with different energies from 1.29 to $5.48 \mathrm{MeV}$.

(1) The etch pits could be recognized at 100 $\%$ efficiency for normal incident $\alpha$-particles within the etching time of 1 hour in $30 \%$ solution of $\mathrm{NaOH}$ at $70^{\circ} \mathrm{C}$ through an optical microscope at 400 magnifications.

(2) The etch pit diameter decreased linearly with the $\alpha$-energy for the etching time of 1,2 and 3 hours. This fact suggested the possibility of the energy estimation through the measurement of etch pit diameter.

(3) The estimated energy resolution was about 1.8 MeV for the etching time of 1,2 and 3 hours.

\section{Acknowledgements}

The authors would like to thank Dr. C. Mori of Nagoya University who gave helpful discussions and advices to complete the paper.

\section{References}

1) T. Hayashi: Oyo Butsuri, 49, 705(1980) (in Japanese)

2) E. Granzer, et al.: "Solid State Nuclear Track Detector", Pergamon Press, Oxford (1978)

3) H.A. Khan and S.A. Durrani: Nucl. Instrum. Methods, 114, 291 (1974)

4) B.G. Cartwright, et al.: ibid., 153, 457 (1978)

5) N. Ishigure and O. Matsuoka: Radioisotopes, 30, 489 (1981)

6) M. Sakanoue: "Ryushi Track to Sono Oyo", p. 42, Nankodo, Tokyo (1973) (in Japanese)

7) R.L. Fleischer, et al.: Phys. Rev., 563, 188, (1969) 
要旨

\title{
1.29MeV から 5.48MeV の $\boldsymbol{a}$ 粒子に対する CR-39 プラスチック \\ のエッチピット径のエネルギー依存性
}

\author{
石榑信人，松岡 理
}

放射線医学総合研究所内部被ばく研究部

260 千葉市穴川4-9-1

CR-39 プラスチックに $\alpha$ 粒子ビームを垂直に照射し，生ずるェッチピットについて，直径の $\alpha$ 粒 子エネルギー依存性を調べた。 $\alpha$ 粒子のエネルギーを $1.29 \mathrm{MeV}$ から $5.48 \mathrm{MeV}$ の間で変化させ, エッチングには $70^{\circ} \mathrm{C}$ の $30 \% \mathrm{NaOH}$ 水溶液を用いた。結果, エッチング過程の初期に扣いては, 直 径がエネルギーの増加に従い，ほほ直線的に隇少することが分かった。この事実は，エッチピット 径の測定によって $\alpha$ 粒子ェネルギーの推定が可能であることを示唆している。そこで，測定したェ

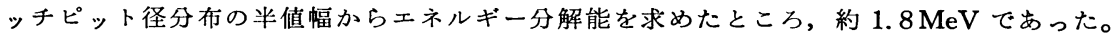

